\title{
Early results of endoscopic lung volume reduction for emphysema
}

Anthony P. C. Yim, MD

Thomas M. T. Hwong, MB, ChB

Tak Wai Lee, MD

Wilson W. L. Li, MSc ${ }^{\mathrm{a}}$

Shirley Lam, RN ${ }^{\mathrm{a}}$

Tai Kong Yeung, $M D^{b}$

David S. C. Hui, MD

Fanny W. S. Ko, MD

Alan D. L. Sihoe, MB, BChir ${ }^{\mathrm{a}}$

Kin Hoi Thung, MB, $\mathrm{ChB}^{\mathrm{a}}$

Ahmed A. Arifi, MD

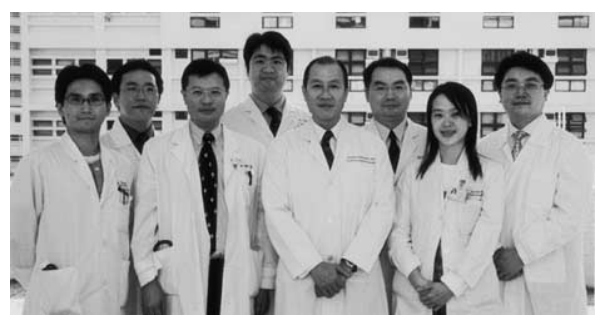

Background: We determined the feasibility, safety, and short-term efficacy of bronchoscopic placement of a one-way endobronchial valve in selected bronchopulmonary segments as an alternative to surgical lung volume reduction.

Methods: A total of 21 patients with incapacitating emphysema who underwent this procedure were studied. All patients had placement of the endobronchial valves into the most emphysematous lung segments. We recorded any major complications or deaths attributed to the procedure and analyzed (1) improvements in the spirometric and functional parameters and quality of life and (2) the radiologic changes compared with the baseline data at 30 and 90 days.

From the Division of Cardiothoracic Surgery, Department of Surgery, ${ }^{\mathrm{a}}$ the Department of Diagnostic and Organ Imaging, ${ }^{b}$ and the Department of Medicine and Therapeutics, ${ }^{c}$ Prince of Wales Hospital, The Chinese University of Hong Kong, Shatin, Hong Kong, China.

Anthony P. C. Yim is currently a consultant to Emphasys Medical (Redwood City, Calif). This study was partially funded by the company, but it had no role in the data collection, analysis, interpretation, or writing of this report.

Received for publication June 25, 2003; revisions requested Sept 3, 2003; revisions received Oct 2, 2003; accepted for publication Oct 3, 2003.

Address for reprints: Anthony P. C. Yim, MD, Department of Surgery, The Chinese University of Hong Kong, Prince of Wales Hospital, Shatin, Hong Kong SAR, China (E-mail: yimap@cuhk.edu.hk).

J Thorac Cardiovasc Surg 2004;127: 1564-73

$0022-5223 / \$ 30.00$

Copyright (C) 2004 by The American Association for Thoracic Surgery

doi:10.1016/j.jtcvs.2003.10.005
Results: A total of 20 patients had complete follow-up data. There was no mortality in the group studied. The forced expiratory volume at 1 second, forced expiratory volume at 1 second (percentage of predicted), forced vital capacity, and forced vital capacity (percentage of predicted) all improved significantly at 90 days $(0.73 \pm 0.26$ $\mathrm{L}$ vs $0.92 \pm 0.34 \mathrm{~L}[P=.009] ; 33.3 \% \pm 11.9 \%$ vs $42.2 \% \pm 15.0 \%[P=.006] ; 1.94$ $\pm 0.62 \mathrm{~L}$ vs $2.25 \pm 0.61 \mathrm{~L}[P=.015] ;$ and $63.3 \% \pm 17.6 \%$ vs $73.9 \% \pm 17.1 \%[P$ $=.012]$, respectively). The 6-minute walking distance improved at 30 and 90 days $(251.6 \pm 100.2 \mathrm{~m}$ vs $306.3 \pm 112.3 \mathrm{~m}$ and $322.3 \pm 129.7 \mathrm{~m} ; P=.012$ and $P=$ $.003)$. The results of the 36-Item Short-Form Health Survey and the St George Respiratory Questionnaire showed significant improvements at 90 days. The Medical Research Council dyspnea grade also improved significantly at 30 and at 90 days $(P=.006$ and $P=.003$, respectively).

Conclusions: Endobronchial valve placement is a safe procedure, with significant short-term improvements in functional status, quality of life, and relief of dyspnea in selected patients with emphysema. A larger study with long-term follow-up is therefore warranted.

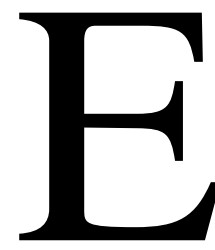

mphysema continues to be a major cause of morbidity and mortality in developed countries. The disease affects approximately 2 million people alone in the United States, with associated costs of US $\$ 2.5$ billion annually, and nearly 17,000 deaths each year are attributed to emphysema. ${ }^{1}$ Despite the controversies, lung volume reduction surgery (LVRS) has been shown to be beneficial to selected patients with end-stage emphysema when medical therapy has failed. ${ }^{2,3}$ The operation was 


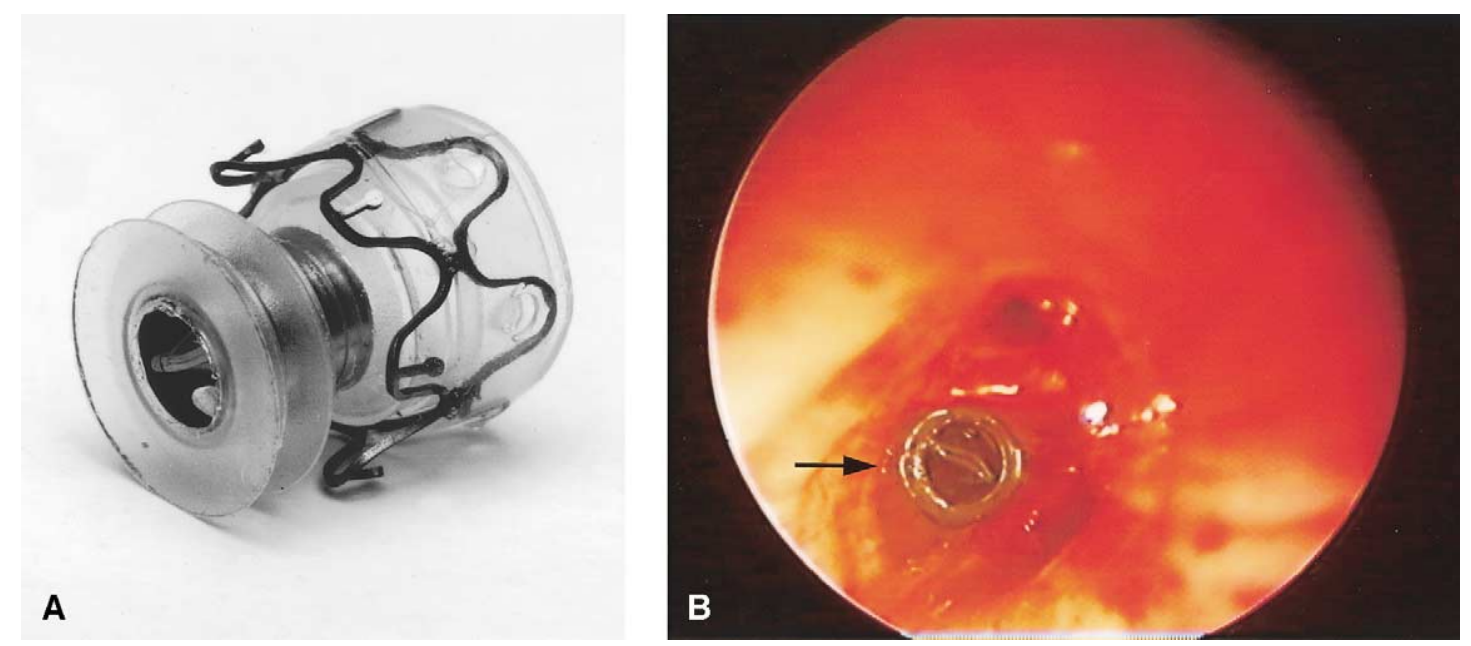

Figure 1. A, Endobronchial valve (Emphasys, Redwood City, Calif). B, Bronchoscopic view showing the endobronchial valve after placement in the target bronchial segment (black arrow).

popularized by Cooper and associates ${ }^{4}$ in the early 1990 s. The principle of LVRS is that removal of the most diseased parts of the hyperinflated lungs helps to restore the chest wall and diaphragmatic mechanics in respiration.

Nonetheless, the trauma of operation (even with the thoracoscopic approach) means that only a relatively small percentage of patients with severe emphysema would benefit from such treatment. Patients with very low forced expiratory volume at 1 second $\left(\mathrm{FEV}_{1}\right)$ and either homogeneous emphysema or a very low carbon monoxide-diffusing capacity (DLCO) are at high risk of death after LVRS, ${ }^{5}$ and the most recent published data have also indicated that patients with non-upper-lobe disease have a higher operative mortality when undergoing operation. ${ }^{6}$

Recently, several devices have emerged, based on the bronchoscopic approach, as possible alternatives to LVRS. The most studied of these is the Endobronchial Valve (Emphasys Medical Inc, Redwood City, Calif). By placing these one-way endobronchial valves (EBV) bronchoscopically into the most emphysematous lung segments, air is prevented from entering into the isolated segments, but distal bronchial secretions are allowed to escape (Figure 1). The net result is induced atelectasis of the most emphysematous segments and redirection of air flow (or ventilation) to the least emphysematous lung to reproduce the clinical benefits of LVRS without exposing the patients to the risks associated with a major operation.

Fann and colleagues ${ }^{7}$ conducted an animal experiment with EBV in which 9 sheep underwent placement of 40 valves in the bronchopulmonary segments. The animals were serially killed from 1 week to 6 months. Both lungs with the trachea were explanted en bloc and then fixed in formalin. All but 3 valve devices were structurally intact and well seated in the bronchial lumen. The 3 valves were coughed out. Evidence of gross collapse was seen distal to $34(85 \%)$ of 40 valve devices on thoracotomy, whereas histologic atelectasis was evident in lung segments distal to 36 devices $(90 \%)$ after fixation.

Toma and colleagues ${ }^{8}$ were the first to report on the clinical experience of this device in a pilot study involving 8 patients with severe emphysema. All had unilateral implantation of the one-way valves. There were no deaths, and pneumothorax was the only reported complication. There was an improvement of the median $\mathrm{FEV}_{1}$ at follow-up after 4 weeks. Likewise, Snell and colleagues ${ }^{9}$ reported on 10 patients and showed improvement in gas transfer. These studies paved the way for a larger clinical study on safety and feasibility, which forms the basis of this report.

\section{Patients and Methods}

We conducted a prospective, nonrandomized, single-center longitudinal cohort study to evaluate the efficacy and safety of endoscopic LVRS by placement of EBVs via rigid bronchoscopy. During the 12-month period from April 2002 to March 2003, a total of 62 patients with incapacitating emphysema who were receiving maximal medical therapy were initially recruited for evaluation. Only 21 patients were finally included in the study on the basis of our selection criteria (Table 1).

Each patient was clinically assessed jointly by the principal investigator (A.P.C.Y.) and a designated team of thoracic surgeons, pulmonologists, and a radiologist. All patients had a computed tomographic (CT) scan of the thorax and a ventilationperfusion $(\dot{\mathrm{V}} / \mathrm{Q})$ scan before and then 30 and 90 days after the placement of these valves. A single-detector spiral CT scanner (HiSpeed Advantage RP Scanner; GE Medical Systems, Milwaukee, Wis) with collimation of $5 \mathrm{~mm}$ and pitch at 2:1 was used. For the $\dot{V} / \mathrm{Q}$ scan, $40 \mathrm{mCi}$ of technetium Tc $99 \mathrm{~m}$ diethylenetriamine pentaacetic acid aerosol was used for the ventilation scan, whereas $5 \mathrm{mCi}$ of ${ }^{99 \mathrm{~m}} \mathrm{Tc}$-labeled macroaggregated albumin was used for the 


\section{TABLE 1. Inclusion and exclusion criteria of the EBV study}

Inclusion criteria
Symptomatic emphysema
Age 50 to $80 \mathrm{y}$
Patient has shortness of breath on routine daily activities
despite maximal medical therapy
Heterogeneous disease on pulmonary CT and $\dot{\mathrm{V}} / \mathrm{O}$ scan
Exclusion criteria $^{\text {FEV }}<_{1}<20 \%$ of predicted value
Hypercapnea with $\mathrm{PaCO}_{2}>55 \mathrm{~mm} \mathrm{Hg}$
Diffusion capacity $<25 \%$ of predicted value
Pulmonary hypertension
Evidence of active pulmonary infection
Patient cannot or will not comply with follow-up
investigations

$E B V$, Endobronchial valve; $C T$, computed tomographic; $\dot{V} / \dot{Q}$, ventilationperfusion; $F E V_{1}$, forced expiratory volume in 1 second.

perfusion scan. The signals were then acquired by using a dualhead gamma camera equipped with a low-energy parallel hole general purpose collimator. The energy was set at $140 \mathrm{keV}$ with a $20 \%$ symmetrical window, and the images were stored in the format of a $128 \times 128$ matrix. All the radiologic examinations were then reviewed by 1 radiologist (T.K.Y.).

Full pulmonary function tests, including arterial blood gas measurements, were obtained for each patient. Transthoracic echocardiography was performed to assess right heart function and to rule out pulmonary hypertension. Baseline 6-minute walking distance (6MWD) was recorded as an assessment of exercise tolerance. Quality-of-life assessment by using the 36-Item Short-Form Health Survey (SF-36) and the St George Respiratory Questionnaire (both validated for Chinese patients) ${ }^{10,11}$ was undertaken. The degree of dyspnea experienced by each patient was measured by the Medical Research Council dyspnea grade.

The primary end point was any major complication or death attributed to the procedure within the study period. The secondary end points of the study were related to the degree of improvement in the lung function, 6MWD, and health-related quality of life (HRQOL) when compared with the baseline data at 30 and 90 days. The results were analyzed with SPSS for Windows version 11.0 (SPSS Inc, Chicago, Ill).

The protocol was formally approved by the University ethical committee (equivalent to the institutional review board). Nearly all these patients (except 1 with pleurodesis [patient 7] and another who already had LVRS [patient 17]) were candidates for LVRS. All patients knew and understood LVRS. Our procedure was offered to them as a new, investigational, and possibly alternative procedure. They understood that LVRS remained an option if this failed. All patients were given a choice of therapy, but none declined this procedure when it was offered. Informed consent was obtained from each patient.

\section{Procedure}

The procedure was performed in the operating room under total intravenous anesthesia with 2,6-dispropylphenol or propofol (Diprivan). The patient was kept in assisted spontaneous ventilation throughout the procedure and placed supine with the head slightly extended. The target areas for EBV placement were pre- viously selected primarily on the basis of V/Q scan in conjunction with pulmonary CT scan. A ventilating rigid bronchoscope with a Hopkins telescope (Efer-Dumon Bronchoscope; Efer, La Ciotat, France) was introduced through the mouth into the airway and was then connected to a 3-chip camera system (Stryker 784; Stryker, Kalamazoo, Mich) with the tip of the bronchoscope positioned at the target lobar orifice (usually one of the upper lobes). The rigid telescope was then exchanged for a flexible bronchoscope, which passed through the rigid bronchoscope to reach each of the target segmental bronchial orifices. A guide wire (0.035-inch external diameter) was threaded through the instrument channel of the flexible bronchoscope into the segmental bronchus. With a modified Seldinger technique, a carrier loaded with the EBV of the appropriate size (3 diameter sizes of 4.0-5.5 mm, 5.0-7.0 mm, and 6.5-8.5 $\mathrm{mm}$ are available) was placed at the segmental bronchial orifice, and the EBV was deployed. The entire procedure was visually monitored by the video bronchoscope. Depending on the exact morbid anatomy, 1 or more valves were placed in the endobronchial tree. For some patients, some segments appeared to be more affected than others within the same lobe (especially for the lower lobe). Overall, 28 lobes were targeted in the 20 patients. Complete lobar occlusion was undertaken in 16 lobes, and 45 valves were placed ( 2.81 valves per lobe targeted). Incomplete lobar occlusion was performed in the remaining 12 lobes, and 32 valves were used (2.67 valves per lobe targeted). We placed the valves only in the most affected segments, rather than indiscriminately in all segments of the lobe. In 1 patient (patient 17), we were unable to place the valve at the apical segment of the right upper lobe because of technical reasons - the guide wire flipped out of the target segment every time as the introducer was advanced.

\section{Postoperative Care and Follow-up}

Chest radiographs and arterial blood gas measurements were performed after surgery, and noninvasive arterial oxygen saturation was continuously monitored. The patients were encouraged to cough (assisted by physiotherapists) to clear any mucus or air remaining behind the valve. All patients received a prophylactic 10-day total course of antibiotics (amoxicillin/clavulanate or roxithromycin), as well as inhaled salbutamol and ipratropium bromide. At the time of discharge, patients were given a wallet card that can be presented to health-care providers, with a brief explanation of the procedure and contact information for the enrolling physician. Participants in the study were invited to contact the hospital for any advice or assistance at any time after the study. Follow-up was weekly for the first month and then twice monthly thereafter, with specific investigations performed at different time points.

\section{Statistical Analysis}

All descriptive statistics were expressed as mean \pm SD for continuous variables and as median (range) for ordinal data. Paired 2-tailed $t$ tests were used to analyze quantitative continuous variables comparing the means for the group. Repeated-measures analysis of variance was performed to compare the means of the variables that had been measured at more than 1 occasion for each individual at the 3 time points (before the procedure and 30 and 90 days after the procedure). Bonferroni correction was used to adjust 
the observed significance level when multiple comparisons of the means were made. The Friedman test and the Wilcoxon signedrank test were used for ordinal variables. All statistical analysis was performed with SPSS for Windows version 11.0.

\section{Results}

A total of 21 patients underwent the procedure described previously. One patient (patient 2) who had some clinical improvement but declined follow-up investigations was excluded from the analysis. For the remaining 20 patients (1 woman only), the mean age was $68.55 \pm 7.40$ years. All but 1 patient were ex-smokers, with a mean pack-years history of $49.5 \pm 25.58$. Bilateral insertions of the EBV were undertaken in 8 of the 20 patients. Two of the patients (patients 13 and 19) were admitted overnight to the intensive care unit for observation because of mild postoperative carbon dioxide retention. The third patient (patient 5) was admitted 8 days after the initial operation because of development of bilateral pneumothorax that required a second operation for resection of a rupture bulla on one side (not in the stented segment). None of the patients required mechanical ventilation during their intensive care unit stay. The mean hospital stay was $5.60 \pm 6.37$ days. There was no procedure-related death. Six patients experienced complications during the immediate postoperative period; pneumothorax was the most common complication (Table 2). Chest drains were inserted in all the patients in whom large pneumothoraces developed (patients 5, 11, and 13). All patients but 1 showed no active air leak, suggesting that the pneumothorax was caused by induced collapse of the lung segments (Figure 2). Bilateral pneumothoraces developed in 1 patient (patient 5), who, after placement of EBVs to both of the upper lobes, required video-assisted thorascopic surgery exploration and excision of a ruptured bulla in the left lower lobe. All the pneumothoraces resolved by the 1-month follow-up. Bronchoscopic assessment was undertaken for the first 6 patients at 1 month, and all demonstrated functioning valves with no evidence of displacement. Because the compliance for this particular follow-up procedure was poor, the procedure was not performed for the remaining patients.

\section{Spirometric and Functional Assessments}

There were significant improvements in the mean value of $\mathrm{FEV}_{1}$ (percentage of predicted) and forced vital capacity (percentage of predicted) at each follow-up time point (Table 3). The mean value of $\mathrm{FEV}_{1}$ was improved by $15 \%$ at 30 days $(0.73 \pm 0.26 \mathrm{~L}$ vs $0.84 \pm 0.27 \mathrm{~L})$ and by $26 \%$ at 90 days $(0.73 \pm 0.26 \mathrm{~L}$ vs $0.92 \pm 0.34 \mathrm{~L})$, and this improvement was significant at 90 days $(P=.009)$. The mean value of forced vital capacity also increased and became statistically significant at 90 days $(1.94 \pm 0.62 \mathrm{~L}$ vs $2.25 \pm 0.61$ $\mathrm{L} ; P=.015)$. Although there was a trend of improvement in the mean DLCO value by $15 \%$ and $13 \%$ at 30 and 90 days,

\section{TABLE 2. Patient characteristics (20 cases)}

\begin{tabular}{cclcl}
\hline $\begin{array}{c}\text { Patient } \\
\text { no. }\end{array}$ & $\begin{array}{c}\text { No. } \\
\text { valves }\end{array}$ & $\begin{array}{l}\text { Position } \\
\text { of valves }\end{array}$ & $\begin{array}{c}\text { Postprocedure } \\
\text { length of stay } \\
\text { (d) }\end{array}$ & Perioperative complications \\
\hline 1 & 2 & RLL & 1 & None \\
3 & 7 & RUL, LUL & 3 & Right pneumothorax \\
4 & 2 & RLL & 3 & None \\
5 & 5 & RUL, LUL & 29 & Bilateral pneumothoraces \\
& & & & CO ${ }_{2}$ retention \\
6 & 6 & RLL, LLL & 5 & None \\
7 & 4 & RUL & 5 & None \\
8 & 6 & LLL & 2 & None \\
9 & 6 & RUL, LUL & 10 & Sputum retention \\
10 & 4 & LUL & 14 & None \\
11 & 4 & RUL & 5 & Right pneumothorax \\
12 & 6 & RUL, LUL & 2 & None \\
13 & 4 & LLL & 3 & Left pneumothorax, CO ${ }_{2}$ \\
& & & & retention \\
14 & 4 & LLL & 2 & None \\
15 & 3 & RUL & 1 & None \\
16 & 2 & LUL & 2 & None \\
17 & 3 & RUL & 5 & None \\
18 & 3 & RLL & 3 & None \\
19 & 3 & RUL, LUL & 3 & Bronchospasm, $\mathrm{CO}_{2}$ \\
& & & & retention \\
20 & 8 & RUL, LUL & 7 & None \\
21 & 5 & RUL, LLL & 7 & None \\
\hline
\end{tabular}

$R L L$, Right lower lobe; $R U L$, right upper lobe; $L U L$, left upper lobe; $R L L$, right lower lobe.

*Patient 2 declined follow-up investigations and so was excluded from the study.

respectively, after the procedure, these changes were not statistically significant. Likewise, lung volumes (measured by body plethysmography) demonstrated a reduction of the residual volume and the total lung capacity, but the results did not reach statistical significance. Exercise tolerance as measured by the 6MWD test demonstrated an improvement of $22 \%$ at 30 days $(251.6 \pm 100.2 \mathrm{~m}$ vs $306.3 \pm 112.3 \mathrm{~m}$; $P=.012)$ and by $28 \%$ at 90 days (251.6 $\pm 100.2 \mathrm{~m} \mathrm{vs}$ $322.3 \pm 129.7 \mathrm{~m} ; P=.003)$ when compared with baseline.

\section{HRQOL Assessments}

The baseline data of the SF-36 health survey (Appendix 1) suggested an impairment of HRQOL. The lowest scores were recorded in physical function $(30.5 \pm 16.6)$, general health $(32.5 \pm 15.0)$, and role limitation (36.8 \pm 41.1; Table 4). Seven of 9 domains of the SF-36 health survey showed an improvement at 30 days and again at 90 days; physical functioning, change in health, general health, and vitality improved significantly after the procedure at 30 days $(P<$ $.001,<.001,<.001$, and .015 , respectively), and the physical functioning and change in health domains produced a sustainable improvement at 90 days $(P=.003$ and $P<$ .001 , respectively). 

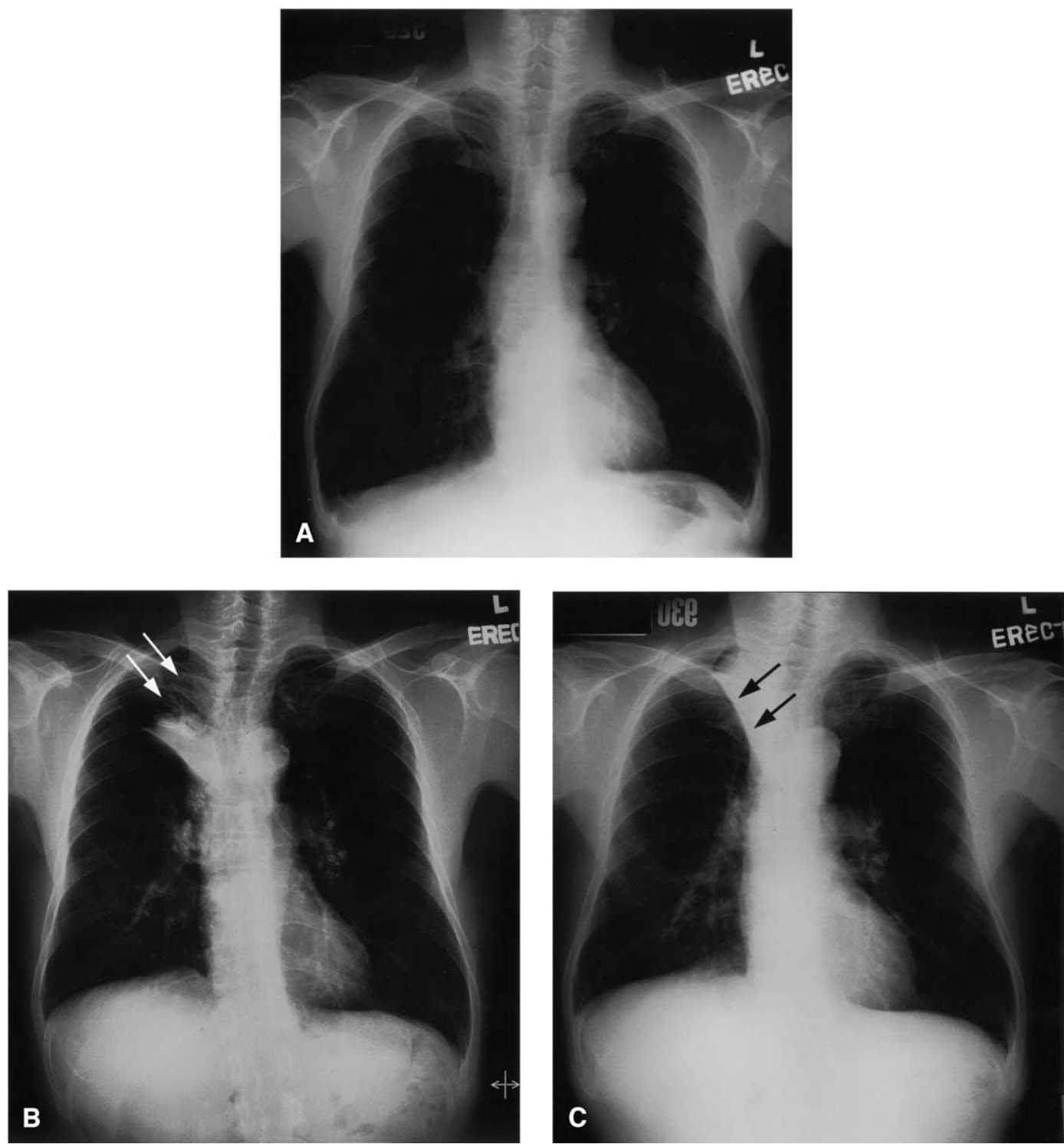

Figure 2. A, Baseline chest radiograph of patient 3 showing hyperinflated lung fields and a flattened diaphragm compatible with emphysema. B, Chest radiograph of the same patient showing collapse of the right upper lobe and an apical pneumothorax (white arrows) at postoperative day 1 after EBV placement in both upper lobes. C, Chest radiograph of the same patient showing progressive collapse of the right upper lobe (without pneumothorax) 1 month after placement of the EBVs.

As for the analysis of the St George Respiratory Questionnaire results (Appendix 2), comparisons of data were not possible before 3 months, because some of the assessments within the questionnaire cannot be fully answered until then. The baseline values suggested a generalized impairment of patients' quality of life; the worst result obtained was in the activity score $(78.9 \pm 16.4)$. Statistically significant improvements in all 4 domains measured were demonstrated at 90 days. Overall, $85 \%$ of the group that reported an improvement of dyspnea at 30 days after the procedure with the Medical Research Council dyspnea grade (Appendix 3) measurement demonstrated an improvement at 30 and 90 days $(P=.006$ and .003 , respectively), thus indicating a significant reduction in the symptoms.

\section{Radiologic Assessments}

EBVs were placed in 28 pulmonary lobes in 20 patients (Table 2). A total of 17 patients with 23 targeted lobes had complete CT evaluation at each follow-up for the degree of induced collapse. The degree of collapse of the respective lobes seen in the CT scans was categorized arbitrarily into 4 grades: grade 0 ( $0 \%$ collapse), grade 1 ( $\leq 25 \%$ collapse), 
TABLE 3. Spirometric functional changes before and after Emphasys bronchial valve placement

\begin{tabular}{|c|c|c|c|c|c|c|c|}
\hline \multirow[b]{2}{*}{ Variable } & \multirow[b]{2}{*}{ Before procedure } & \multirow[b]{2}{*}{ At $1 \mathrm{mo}$} & \multirow[b]{2}{*}{ At $3 \mathrm{mo}$} & \multicolumn{2}{|c|}{$\begin{array}{c}\text { Repeated- } \\
\text { measures analysis }\end{array}$} & \multicolumn{2}{|c|}{$\begin{array}{c}P \text { value (with Bonferroni } \\
\text { correction) }\end{array}$} \\
\hline & & & & $P$ value & $\begin{array}{l}\text { Linear } \\
\text { trend }\end{array}$ & $\begin{array}{c}\text { Comparison } \\
\text { between } \\
\text { before } \\
\text { procedure } \\
\text { and at } 1 \text { mo }\end{array}$ & $\begin{array}{c}\text { Comparison } \\
\text { between } \\
\text { before } \\
\text { procedure } \\
\text { and at } 3 \text { mo }\end{array}$ \\
\hline \multicolumn{8}{|l|}{ Pulmonary function } \\
\hline $\mathrm{FEV}_{1}(\mathrm{~L})$ & $0.73 \pm 0.26$ & $0.84 \pm 0.27$ & $0.92 \pm 0.34$ & .003 & .006 & .075 & .009 \\
\hline $\mathrm{FEV}_{1}(\%$ predicted $)$ & $33.3 \pm 11.9$ & $38.8 \pm 13.2$ & $42.2 \pm 15.0$ & .004 & .004 & .045 & .006 \\
\hline $\mathrm{FVC}(\mathrm{L})$ & $1.94 \pm 0.62$ & $2.12 \pm 0.47$ & $2.25 \pm 0.61$ & .002 & .002 & .06 & .015 \\
\hline FVC (\% predicted) & $63.3 \pm 17.6$ & $70.5 \pm 14.3$ & $73.9 \pm 17.1$ & $<.001$ & .002 & .021 & .012 \\
\hline TLC (L) & $7.03 \pm 1.60$ & $6.50 \pm 1.77$ & $6.58 \pm 1.48$ & .895 & .930 & 1.041 & 1.446 \\
\hline TLC (\% predicted) & $146.4 \pm 30.8$ & $144.6 \pm 60.9$ & $141.1 \pm 40.4$ & .860 & .869 & 1.263 & 2.16 \\
\hline $\mathrm{DLCO}(\mathrm{mL} / \mathrm{min} / \mathrm{mm} \mathrm{Hg})$ & $8.00 \pm 4.13$ & $9.18 \pm 4.12$ & $9.06 \pm 4.09$ & .504 & .339 & 1.677 & 1.179 \\
\hline DLCO (\% predicted) & $50.8 \pm 21.0$ & $59.6 \pm 22.0$ & $60.6 \pm 24.4$ & .157 & .133 & .54 & .426 \\
\hline $\mathrm{RV}(\mathrm{L})$ & $4.98 \pm 1.49$ & $4.85 \pm 1.97$ & $4.43 \pm 1.43$ & .851 & .770 & 1.065 & 1.14 \\
\hline RV (\% predicted) & $368.9 \pm 127.4$ & $350.9 \pm 191.2$ & $326.7 \pm 133.9$ & .876 & .987 & 1.332 & 1.539 \\
\hline $\mathrm{RV} / \mathrm{TLC}$ & $0.71 \pm 0.12$ & $0.72 \pm 0.13$ & $0.67 \pm 0.10$ & .699 & .565 & 1.392 & .885 \\
\hline \multicolumn{8}{|l|}{ Exercise tolerance } \\
\hline 6MWD (m) & $251.6 \pm 100.2$ & $306.3 \pm 112.3$ & $322.3 \pm 129.7$ & $<.001$ & $<.001$ & .012 & .003 \\
\hline
\end{tabular}

Data are presented as mean $\pm \mathrm{SD}$. FEV , Forced expiratory volume in 1 second; FVC, forced vital capacity; TLC, total lung capacity; DLCO, carbon monoxide-diffusing capacity; $R V$, residual volume; $6 \mathrm{MWD}, 6$-min walking distance.

TABLE 4. Health-related quality of life changes before and after Emphasys bronchial valve placement

\begin{tabular}{|c|c|c|c|c|c|c|c|}
\hline \multirow[b]{2}{*}{ Variable } & \multirow[b]{2}{*}{ Before procedure } & \multirow[b]{2}{*}{ At $1 \mathrm{mo}$} & \multirow[b]{2}{*}{ At 3 mo } & \multicolumn{2}{|c|}{$\begin{array}{l}\text { Repeated-measures } \\
\text { analysis }\end{array}$} & \multicolumn{2}{|c|}{$\begin{array}{c}P \text { value (with Bonferroni } \\
\text { correction) }\end{array}$} \\
\hline & & & & $P$ value & $\begin{array}{l}\text { Linear } \\
\text { trend }\end{array}$ & $\begin{array}{c}\text { Comparison } \\
\text { between } \\
\text { before } \\
\text { procedure } \\
\text { and at } 1 \text { mo }\end{array}$ & $\begin{array}{c}\text { Comparison } \\
\text { between } \\
\text { before } \\
\text { procedure } \\
\text { and at } 3 \text { mo }\end{array}$ \\
\hline \multicolumn{8}{|l|}{ SF-36* } \\
\hline Physical functioning & $30.5 \pm 16.6$ & $57.5 \pm 27.0$ & $63.1 \pm 32.0$ & $<.001$ & $<.001$ & $<.001$ & .003 \\
\hline $\begin{array}{l}\text { Role limitation due to } \\
\text { physical problems }\end{array}$ & $36.8 \pm 41.1$ & $65.6 \pm 40.7$ & $56.9 \pm 46.8$ & .090 & .095 & .288 & .378 \\
\hline Bodily pain & $94.7 \pm 14.7$ & $89.8 \pm 20.6$ & $92.9 \pm 20.8$ & .189 & .808 & 1.725 & 1.152 \\
\hline General health & $32.5 \pm 15.0$ & $61.9 \pm 21.6$ & $44.7 \pm 26.0$ & $<.001$ & .012 & $<.001$ & .243 \\
\hline Vitality & $44.2 \pm 21.0$ & $64.4 \pm 14.8$ & $60.0 \pm 27.2$ & .005 & .013 & .015 & .357 \\
\hline Social functioning & $48.7 \pm 30.6$ & $69.5 \pm 26.2$ & $71.5 \pm 39.3$ & .004 & .002 & .123 & .123 \\
\hline $\begin{array}{l}\text { Role limitation due to } \\
\text { emotional problems }\end{array}$ & $70.2 \pm 44.3$ & $85.4 \pm 32.1$ & $70.4 \pm 45.6$ & .400 & .348 & .654 & 2.415 \\
\hline Mental health & $69.3 \pm 17.4$ & $79.5 \pm 14.5$ & $76.4 \pm 22.4$ & .042 & .042 & .114 & .822 \\
\hline Change in health & $38.9 \pm 17.0$ & $85.0 \pm 21.3$ & $74.4 \pm 28.9$ & $<.001$ & $<.001$ & $<.001$ & $<.001$ \\
\hline \multicolumn{8}{|l|}{ SGROt } \\
\hline Symptoms score & $52.8 \pm 17.1$ & $\mathrm{~N} / \mathrm{A}$ & $39.2 \pm 27.4$ & \multicolumn{2}{|c|}{$\mathrm{N} / \mathrm{A}$} & $\mathrm{N} / \mathrm{A}$ & .025 \\
\hline Activity score & $78.9 \pm 16.4$ & $\mathrm{~N} / \mathrm{A}$ & $52.8 \pm 28.2$ & \multicolumn{2}{|c|}{$\mathrm{N} / \mathrm{A}$} & $\mathrm{N} / \mathrm{A}$ & $<.001$ \\
\hline Impact score & $56.7 \pm 20.7$ & $\mathrm{~N} / \mathrm{A}$ & $31.8 \pm 26.4$ & \multicolumn{2}{|c|}{$\mathrm{N} / \mathrm{A}$} & $\mathrm{N} / \mathrm{A}$ & .014 \\
\hline Total score & $62.7 \pm 14.2$ & $\mathrm{~N} / \mathrm{A}$ & $39.3 \pm 24.4$ & \multicolumn{2}{|c|}{$\mathrm{N} / \mathrm{A}$} & $\mathrm{N} / \mathrm{A}$ & .003 \\
\hline MRC grade $\ddagger$ & $3(2-5)$ & $2(1-5)$ & $1(1-4)$ & \multicolumn{2}{|c|}{$\mathrm{N} / \mathrm{A}$} & .006 & .003 \\
\hline
\end{tabular}

Data are presented as mean \pm SD or median (range). $N / A$, Not available.

*The 36-Item Short-Form Health Survey (SF-36) scores range from 0 to 100 . Higher scores represent higher levels of functioning/quality of life and fewer symptoms.

tSt George Respiratory Questionnaire (SGRQ) scores range from 0 to 100. Lower scores represent higher levels of functioning/quality of life and fewer symptoms.

¥Medical Research Council (MRC) grades range from 1 to 5 . Lower scores represent fewer symptoms. 
TABLE 5. Summary of CT findings after Emphasys bronchial valve placement

\begin{tabular}{lcc}
\hline Grade & $\begin{array}{c}\text { No. of lobes } \\
\text { at } \mathbf{1} \text { mo }\end{array}$ & $\begin{array}{c}\text { No. of lobes } \\
\text { at 3 mo }\end{array}$ \\
\hline Grade $0(0 \%$ collapse $)$ & 15 & 13 \\
Grade $1(<25 \%$ collapse $)$ & 3 & 6 \\
Grade $2(25 \%$ to $75 \%$ collapse $)$ & 1 & 0 \\
Grade $3(>75 \%$ collapse $)$ & 4 & 4 \\
\hline
\end{tabular}

$C T$, Computed tomography.

grade 2 ( $25 \%$ to $75 \%$ collapse), and grade 3 (>75\% collapse). It is interesting to note that only $10(43 \%)$ of the 23 lobes showed some degree of collapse after the placement of the EBVs during the entire follow-up period. Six of these 10 lobes remained unchanged throughout the follow-up period, whereas 2 lobes showed mild re-expansion and the remaining 2 showed no collapse at all in the first month but had a delayed collapse at the third month (Table 5). For those 13 pulmonary lobes that showed no collapse throughout the 3-month follow-up period, the serial $\dot{V} / \mathrm{Q}$ scintigraphic findings of the respective lobes also remained static.

\section{Discussion}

The concept of nonresectional lung volume reduction has emerged recently, and new devices and strategies were developed to achieve endoscopic lung volume reduction without the need for open operation. These include induced atelectasis by using endobronchial sealants, occluders, or valves and creation of extra-anatomic tracts within the major airway to facilitate expiratory airflow.

However, most of the new devices and strategies mentioned previously remain in the animal experimentation phase, and very few have come to clinical study. Early work in the area of internal isolation of lung segments by Sabanathan and associates ${ }^{12}$ with 2 different designs of bronchial blockers (silicone balloons and occluded stents) in human subjects demonstrated improvement of symptoms in 5 of 8 patients. However, prosthesis migration, expectoration, and development of pneumonia limited the application of this approach. On the basis of information drawn from that study and results from animal models of bronchoscopic lung volume reduction, an ideal endobronchial device should therefore have the following qualities: (1) it should be effective in achieving and sustaining lung volume reduction, (2) the results should be reproducible, (3) the device should preferably be deployable by using a flexible bronchoscope with the patient under local anesthesia, (4) the device should be easily removable by using a flexible bronchoscope, (5) the design of the device should allow no migration or displacement in the airway, (6) bronchial secretions should be allowed to escape, and (7) there should be no pulmonary infection due to sputum retention. A full discussion of the available prototype devices is beyond the scope of this article, and interested readers are referred to the literature regarding the umbrella valve (Spiration, Inc, Redmond, Wash) ${ }^{13}$ various types of endobronchial blockers, and sealant. ${ }^{14-16}$

An alternative concept of creating extra-anatomic tracts was initially suggested by Macklem ${ }^{17}$ on the basis of the theory that the formation of extra pathways between the lung and the chest wall would allow escape of trapped air and thus improve the expiratory flow. This concept was modified, and extra-anatomic tracts can now be created through the bronchoscope between the major airway and the emphysematous lung parenchyma by using a radiofrequency probe (Broncus Technologies, Mountain View, Calif), and stents are then put in place in these iatrogenic tracts to prevent them from collapsing. Lausberg and colleagues ${ }^{18}$ from the Washington University School of Medicine reported a significant improvement of the $\mathrm{FEV}_{1}$ after nonanatomic tracts were created by using specific radiofrequency probes, followed by placement of expanding stents into each of the passageways by using human emphysematous lungs removed from the time of transplantation. The use of intraoperative endobronchial Doppler imaging is important in guiding the procedure and avoiding vessel perforation in a clinical study. ${ }^{19}$

The data from this study indicated that bronchoscopic placement of the EBVs is a safe procedure, and significant improvements were seen in pulmonary function, exercise tolerance, dyspnea scores, and HRQOL. Furthermore, admission to the intensive care unit is not mandatory, even in these high-risk patients. Only 3 of 20 patients needed admission to the intensive care unit: 2 for overnight observation because of carbon dioxide retention (but did not require mechanical ventilation) and 1 with postoperative pneumothorax (this patient eventually required another operation, as stated previously).

The exact mechanism for the pneumothorax remains unclear. It is almost certainly due to acute lung volume loss secondary to valve placement, but it begs the question why the remaining lung did not rise up to occupy the space. Pleural adhesion is a possible explanation but may be inadequate to account for the frequency of our observation. We do know, however, that there was no buildup of possible pressure in the pneumothorax space, because there was no air leak from the chest drain and because applying gentle suction did not completely resolve the pneumothorax.

Because no pneumonia was identified during the follow-up period, this suggests that bronchial secretion is being cleared in these isolated segments. It is not entirely unexpected that induced lobar collapse was evident on CT scans in only 10 of the 20 patients at 90 days (Figure 3 ). One explanation is that excess collateral airflow occurred in the emphysematous lungs ${ }^{20}$ and prevented the collapse of the target zones in some of our patients. Similar results were 


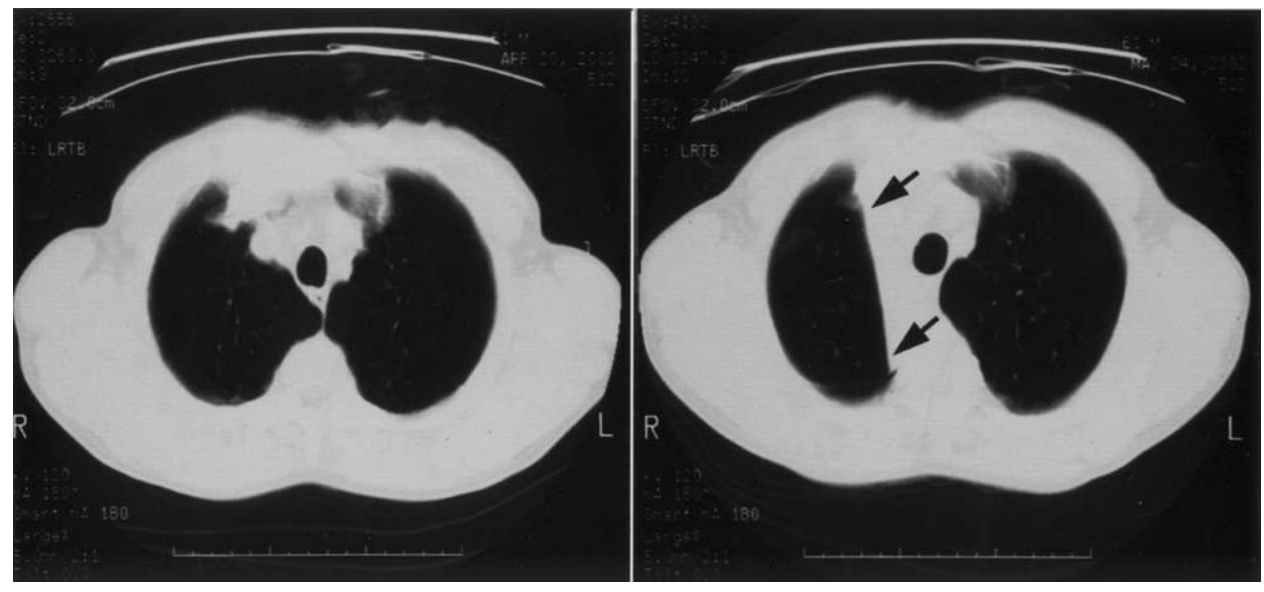

Figure 3. Baseline CT scan (left) and CT scan of the same patient at 1 month (right) after the procedure, showing collapse of the target segments (mainly the apical segment of the right upper lobe; arrows.) The 3-month result was similar to the image at 1 month (not shown).

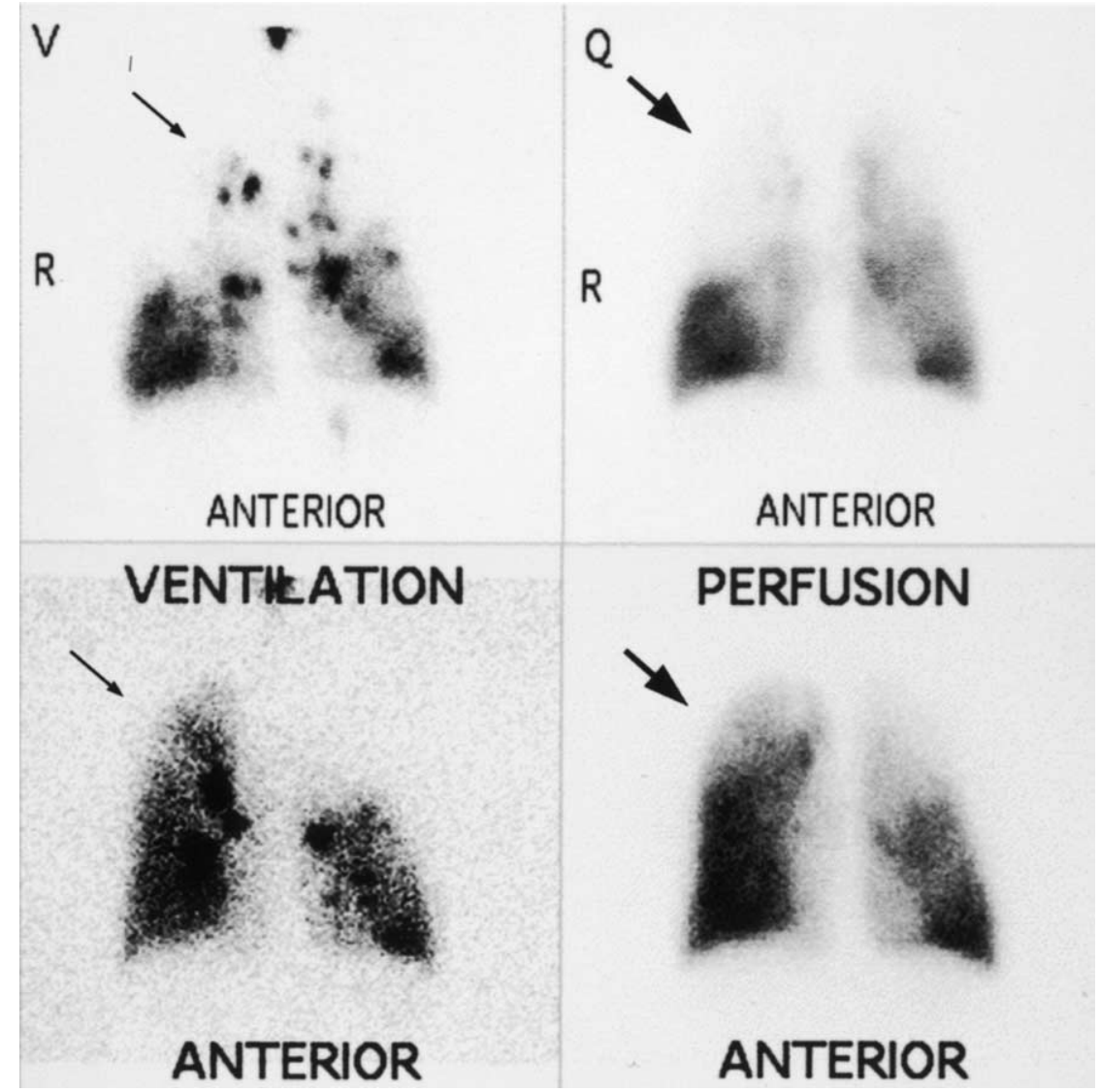

Figure 4. Baseline $\dot{V} / \dot{Q}$ scan (top) of patient 3 showing a heterogeneous emphysema pattern. A $\dot{V} / \dot{Q}$ scan of the same patient at 3 months after EBV placement (bottom) shows an improvement of the ventilation (narrow arrows) and a corresponding improvement of the ventilation (broad arrows) when compared with baseline.

also seen in the pilot study conducted by Toma and colleagues, ${ }^{8}$ in which lobar collapse was evident in only $50 \%$ of the patients by using the same valve. This would have explained the fact that neither residual volume nor total lung capacity showed a significant decrease in our study. Even though segmental collapse is not always present, there is 
nonetheless a trend of improvement in the DLCO. This observation could be explained by airflow being redirected to the relatively healthier portions of the lungs by these one-way valves and hence reducing the $\dot{V} / \dot{Q}$ mismatch (Figure 4). More study is definitely needed in this area.

Three-dimensional CT scans provide a very accurate estimate of lung volume, ${ }^{21}$ and with thin CT thorax slices (collimation of $5 \mathrm{~mm}$ ), good follow-up images can provide an estimation of the degree of emphysema in different segments of the lungs. Follow-up thorax CT at both at 30 and 90 days is essential, because there are cases of reexpansion and delayed collapse.

Radiologically, $\dot{\mathrm{V}} / \dot{\mathrm{Q}}$ scan does not prove to be useful in the follow-up of these patients, because the findings are variable and the scan did not pick up subtle collapse in the lobes. Xenon scan with bronchial blockers may be helpful in delineating the collateral air drift between the segments, and this may help in selecting future patients for the placement of EBVs. Further study on this is currently under way.

In conclusion, this is the first detailed report on the feasibility, short-term outcome, and improvement of HRQOL after EBV placement for emphysema treatment. Our results suggest that a larger multicenter study with long-term follow-up is warranted. Such a trial-the International Endobronchial Valve for Emphysema Palliation Registry—is currently being organized.

The authors thank Albert Cheung from The Centre for Epidemiology and Biostatistics, The Chinese University of Hong Kong, for his advice on and assistance with statistics.

\section{References}

1. National Emphysema Treatment Trial. Emphysema awareness. Available at: URL: http://www.emphysemastudy.org/emphysema.html. Accessed October 28, 2003.

2. Yusen RD, Lefrak SS, Gierada DS, Davis GE, Meyers BF, Patterson $\mathrm{GA}$, et al. A prospective evaluation of lung volume reduction surgery in 200 consecutive patients. Chest. 2003;123:1026-37.

3. Ciccone AM, Meyers BF, Guthrie TJ, Guthrie TJ, Battafarano RJ, Trulock EP, et al. Long term outcome of bilateral lung volume reduction in 250 consecutive patients with emphysema. $J$ Thorac Cardiovasc Surg. 2003; 125:513-25.

4. Cooper JD, Trulock EP, Triantafillou AN, Patterson GA, Pohl MS, Deloney PA, et al. Bilateral pneumonectomy (volume reduction) for chronic obstructive pulmonary disease. J Thorac Cardiovasc Surg. 1995;109:106-19.

5. National Emphysema Treatment Trial Research Group. Patients at high risk of death after lung volume reduction surgery. $N$ Engl J Med. 2001;345:1075-83.

6. National Emphysema Treatment Trial Research Group. A randomized trial comparing lung-volume-reduction surgery with medical therapy for severe emphysema. $N$ Engl J Med. 2003;348:2059-73.

7. Fann JI, Berry GJ, Burdon TA. Bronchoscopic approach to lung volume reduction using a valve device. J Bronchol. In press.

8. Toma TP, Hopkinson NS, Hillier J, Hansell DM, Morgan C, Goldstraw PG, et al. Bronchoscopic volume reduction with valve implants in patients with severe emphysema. Lancet. 2003;361:931-3.

9. Snell G, Holworth L, Borrill ZL, Thomson K, Kalff V, Smith J, et al. The potential for bronchoscopic lung volume reduction using bronchial prosthesis: a pilot study. Chest. 2003;124:1073-80.

10. Lam CL, Gandek B, Ren XS, Chan MS. Tests of scaling assumptions and construct validity of the Chinese (HK) version of the SF-36 Health Survey. J Clin Epidemiol. 1998;51:1139-47.

11. Chan SL, Chan-Yeung MM, Ooi GC, Lam CL, Cheung TF, Lam WK, et al. Validation of the Hong Kong Chinese version of the St. George Respiratory Questionnaire in patients with bronchiectasis. Chest. 2002;122:2030-7.

12. Sabanathan S, Richardson J, Pieri-Davies S. Bronchoscopic lung volume reduction. J Cardiovasc Surg (Torino). 2003;44:101-8.

13. Dillard D, Gonzales X, Devore L, Park M, Park M, Yi S, et al. Evaluation of a novel intra-bronchial valve to produce lung volume reduction. Presented at the 12th World Congress of Bronchology, June 18, 2002; Boston, Mass.

14. Ingenito EP, Reilly JJ, Mentzer SJ, Swanson SJ, Vin R, Keuhn H, et al. Bronchoscopic volume reduction: a safe and effective alternative to surgical therapy for emphysema. Am J Respir Crit Care Med. 2001; 164:295-301.

15. Ingenito EP, Berger RL, Henderson AC, Reilly JJ, Tsai L, Hoffman A. Bronchoscopic lung volume reduction using tissue engineering principles. Am J Respir Crit Care Med. 2003;167:771-8.

16. Toma TP. The flexible bronchoscopic approach to lung volume reduction. Pneumologia. 2001;50:97-100.

17. Macklem P. Collateral ventilation. N Engl J Med. 1978;298:49-50.

18. Lausberg HF, Chino K, Patterson GA, Meyers BF, Toeniskoetter PD, Cooper JD. Bronchial fenestration improves expiratory flow in emphysematous human lungs. Ann Thorac Surg. 2003;75:393-8.

19. Rendina EA, De Giacomo T, Venuta F, Coloni GF, Meyers BF, Patterson GA, et al. Feasibility and safety of the airway bypass procedure for patients with emphysema. J Thorac Cardiovasc Surg. 2003;125:1294-9.

20. Morrell NW, Wignall BK, Biggs T, Seed WA. Collateral ventilation and gas exchange in emphysema. Am J Respir Crit Care Med. 1994; 150:635-41.

21. Rogers RM, Coxson HO, Sciurba FC, Keenan RJ, Whittall KP, Hogg JC. Preoperative severity of emphysema predictive of improvement after lung volume reduction surgery: use of CT morphometry. Chest. 2000;118:1240-7.

\section{Appendix 1: Nine Domains of the Chinese SF-36 Survey Questionnaire}

1. Physical functioning: assesses the individual's ability to perform all physical activities, including events of daily living. A low score means more limitations.

2. Role-physical: assesses the individual's lack of physical ability to fulfill his or her daily roles. A low score means there is a problem.

3. Bodily pain: assesses the results of physical activities. A low score means severe pain.

4. General health: evaluates the personal assessment of physical and mental health. A low score means the person sees his or her health as poor.

5. Vitality: assesses the person's physical and mental wellbeing. A low score means that the individual feels tired and worn out.

6. Social functioning: evaluates the disability to conduct social interaction. A low score suggests extreme limitation.

7. Role-emotional: assesses mental disability. A low score means that a person is unable to fulfill his or her roles because of emotional problems.

8. Mental health: assesses the person's mental function. A low score indicates that an individual feels nervous and depressed most of the time.

9. Change in health: assesses the individual's perception of improvement in health. A low score would indicate that the person feels that there is no improvement in his or her health status. 


\section{Appendix 2: St George Respiratory Questionnaire- Hong Kong}

1. Symptoms: assesses the component of respiratory symptoms (their frequency and severity).

2. Activity: relates to the activities that cause or are limited by breathlessness.

3. Impact: concerns aspects of social functioning and psychological disturbances resulting from the disease.

4. Total score: summarizes the overall impairment and is expressed as a percentage, where $100 \%$ is the worst possible outcome and $0 \%$ indicates the opposite.

\section{Appendix 3: Medical Research Council Grades-Degree of Dyspnea}

Grade 1: not troubled with breathlessness, except on strenuous exertion.

Grade 2: short of breath when hurrying on the level or walking up a slight hill.

Grade 3: patient walks more slowly than most people on the level.

Grade 4: patient has to stop for breathing after walking for approximately 100 yards on the level.

Grade 5: too breathless to leave home or feeling breathless after undressing. 